\title{
Water vapour tomography using GPS phase observations: Results from the ESCOMPTE experiment
}

\section{T. Nilsson \& G. Elgered}

To cite this article: T. Nilsson \& G. Elgered (2007) Water vapour tomography using GPS phase observations: Results from the ESCOMPTE experiment, Tellus A: Dynamic Meteorology and Oceanography, 59:5, 674-682, DOI: 10.1111/j.1600-0870.2007.00247.x

To link to this article: http://dx.doi.org/10.1111/j.1600-0870.2007.00247.x (c) 2007 The Author(s). Published by Taylor \&
Francis.

\section{曲 Published online: 15 Dec 2016.}

Submit your article to this journal $₫$

Џ Article views: 13 


\title{
Water vapour tomography using GPS phase observations: Results from the ESCOMPTE experiment
}

\author{
By T. NILSSON*, L. GRADINARSKY and G. ELGERED, Department of Radio and Space Science, \\ Chalmers University of Technology, Onsala Space Observatory, Onsala, Sweden
}

(Manuscript received 21 September 2006; in final form 22 February 2007)

\begin{abstract}
Global Positioning System (GPS) tomography is a technique for estimating the 3-D structure of the atmospheric water vapour using data from a dense local network of GPS receivers. Several current methods utilize estimates of slant wet delays between the GPS satellites and the receivers on the ground, which are difficult to obtain with millimetre accuracy from the GPS observations. We present results of applying a new tomographic method to GPS data from the Expériance sur site pour contraindre les modèles de pollution atmosphérique et de transport d'emissions (ESCOMPTE) experiment in southern France. This method does not rely on any slant wet delay estimates, instead it uses the GPS phase observations directly. We show that the estimated wet refractivity profiles estimated by this method is on the same accuracy level or better compared to other tomographic methods. The results are in agreement with earlier simulations, for example the profile information is limited above $4 \mathrm{~km}$.
\end{abstract}

\section{Introduction}

Global Navigation Satellite Systems (GNSS), such as the Global Positioning System (GPS) have proven to be useful tools to retrieve the integrated amount of water vapour in the atmosphere (Bevis et al., 1992; Rocken et al., 1995; Emardson et al., 1998; Tregoning et al., 1998). By having measurements of the integrated amount of water vapour in several different directions at several different locations in a local network, it is possible to estimate also the 3-D structure of the atmospheric water vapour by applying tomographic methods. This technique is called GPS tomography (Flores et al., 2001; Troller et al., 2002; Gradinarsky and Jarlemark, 2004; Lutz et al., 2004; Champollion et al., 2005).

For GPS tomography to work the slant wet delays between the GPS satellites and the receivers must be estimated accurately. High accuracy is needed since the geometry of the problem of retrieving the vertical profile of the atmospheric water vapour is typically very weak (especially for relatively flat GPS networks). The normal way to obtain the slant wet delays is to model them as a function of a few parameters, normally zenith wet delays and linear horizontal gradients, and estimate these together with other unknown parameters in a GPS data analysis. Due to the simplicity of the model, the estimated slant wet delays may not

\footnotetext{
*Corresponding author.

e-mail: tobias@oso.chalmers.se

DOI: $10.1111 / \mathrm{j} .1600-0870.2007 .00247 . x$
}

have sufficient accuracy to be used in GPS tomography. To improve the slant wet delay estimates, the residuals of the processing can be assumed to contain the unmodelled part of the slant wet delays (Flores et al., 2001). However, this is formally not a correct technique (Elósegui and Davis, 2003; Nilsson, 2005). To avoid this problem we have developed a new method that does not rely on accurate estimations of the slant wet delays, instead it uses the GPS phase observations directly.

This method was presented by Nilsson (2005). Nilsson and Gradinarsky (2006) showed by simulations that the refractivity can be retrieved with a mean estimation error in the range $1-5 \mathrm{~mm} \mathrm{~km}^{-1}$, depending on the number of stations in the network and the complexity of the refractivity field. The simulations also showed that the sensitivity decreases with height, with very little sensitivity above $4 \mathrm{~km}$ (for a relatively flat network). Furthermore, the simulations showed that the sensitivity is increased if data from other GNSS, like the future European system Galileo, are included. This is especially true in the cases when the sensitivity using GPS only was low.

In this work, we apply this new method using real GPS data from the ESCOMPTE experiment conducted near the city of Marseille, France in June 2001 (Cros et al., 2004; Atmospheric Research, 2005; Bock et al., 2004, http://medias.obsmip.fr/escompte/index). Preliminary results from $1 \mathrm{~d}$ of this experiment (26 June 2001) were presented by Nilsson et al. (2005). In this work, we present more complete results based on data from several days and compare the retrieved vertical profiles of 
the wet refractivity to those obtained from radiosonde data as well as other tomographic methods.

\section{Theory}

The carrier phase of a GPS signal from satellite $j$ observed by receiver $i, L_{i}^{j}$, can be expressed as (Hofmann-Wellenhof et al., 2001):

$L_{i}^{j}=\rho_{i}^{j}+c \tau_{i}-c \tau^{j}+l_{i}^{j}+I_{i}^{j}+M_{i}^{j} \lambda+\epsilon_{i}^{j}$,

where $\rho_{i}^{j}$ is the distance between the satellite and the receiver; $c$ is the speed of light in vacuum; $\tau_{i}$ and $\tau^{j}$ are the clock errors in the receiver and the satellite, respectively; $l_{i}^{j}$ is the delay in the neutral atmosphere; $I_{i}^{j}$ is the delay in the ionosphere; $M_{i}^{j}$ is the integer ambiguity; $\lambda$ is the wavelength of the signal; and $\epsilon_{i}^{j}$ is the phase measurement error. For phase measurements from a local network of GPS receivers, $\rho_{i}^{j}$ will be known if the satellite and the receiver positions are accurately known, the hydrostatic part of the atmospheric delay could be removed using the surface pressure, and measurements at two (or more) frequencies are combined in order to remove the ionospheric delay. Many methods exist for estimating integer ambiguities. In this work, we have used the method described by Nilsson and Gradinarsky (2006) where double differences are used to obtain $M_{i}^{j}$. Estimating and removing all these quantities from $L_{i}^{j}$ in eq. (1), we obtain modified phase observations $\tilde{L}_{i}^{j}$ of the form (Nilsson and Gradinarsky, 2006; Nilsson, 2005):

$\tilde{L}_{i}^{j}=c \tilde{\tau}_{i}-c \tilde{\tau}^{j}+\left(l_{w}\right)_{i}^{j}+\tilde{\epsilon}_{i}^{j}$,

where $\tilde{\tau}_{i}$ and $\tilde{\tau}^{j}$ are modified clock errors, containing the clock errors and other quantities behaving like clock errors. The wet atmosphere can be approximated by making a discretization dividing the troposphere into a number of boxes, referred to as voxels (volume pixels). The wet refractivity in these voxels is assumed constant. Hence, the slant wet delay between satellite $i$ and receiver $j$ can be expressed as a linear combination of the refractivities of the voxels:

$\left(l_{w}\right)_{i}^{j}=10^{-6} \sum_{k} N_{w}(k) x_{i}^{j}(k)$,

where $N_{w}(k)$ is the refractivity of voxel $k\left(N_{w}=10^{6}\left(n_{w}-1\right), n_{w}\right.$ being the wet part of the refractive index $)$ and $x_{i}^{j}(k)$ is the distance travelled by the signal in voxel $k$. Combining eq. (3) and eq. (2), the modified phase observations $\tilde{L}_{i}^{j}$ are described as linear combinations of the modified clock errors and the refractivities of the voxels, plus modified phase measurement errors. Having several observations, we obtain a linear system of equations. Solving the system gives the wet refractivity field (as well as the modified clock errors).

However, the linear system of equations will in general be ill conditioned due to the poor geometry of the tomographic problem. To overcome this problem, additional information (constraints) need to be added to the system. One possibility to use a Kalman filter (Brown and Hwang, 1997) with a covariance matrix obtained using theory of atmospheric turbulence. This is done using expressions relating the refractivity at two different points in space, $\mathbf{r}_{1}$ and $\mathbf{r}_{2}$, as (Treuhaft and Lanyi, 1987):

$\left\langle\left(N_{w}\left(\mathbf{r}_{1}\right)-N_{w}\left(\mathbf{r}_{2}\right)\right)^{2}\right\rangle=10^{12} C_{n}^{2} \frac{\left|\mathbf{r}_{1}-\mathbf{r}_{2}\right|^{2 / 3}}{1+\left(\frac{\left|\mathbf{r}_{1}-\mathbf{r}_{2}\right|}{L}\right)^{2 / 3}}$,

where $\langle\ldots\rangle$ denotes expectation value, $C_{n}$ is the wet refractivity structure constant, and $L$ is the turbulence saturation scale length. In this work, we use $L=3000 \mathrm{~km}$, and $C_{n}$ is modelled as $1.2 \cdot 10^{-7} \mathrm{~m}^{-1}$ at the ground and decaying exponentially with a scale height of $2 \mathrm{~km}$. Furthermore, we use a slightly modified version of eq. (4) to account for, for example the difference in turbulence in the horizontal and vertical directions (for details see Nilsson, 2005). To model the variation in time, we assume that such variation are due to the air moving with the wind speed, assumed to be $8 \mathrm{~m} \mathrm{~s}^{-1}$.

\section{Results}

We have applied the new method to data from the ESCOMPTE experiment conducted in June 2001 in southern France around the city of Marseille (Cros et al., 2004). The network consisted of 18 GPS receivers (see Fig. 1), although during the period investigated here, there were at most 17 receivers working at the same time. All receivers except one were in an area of approximately $20 \times 20 \mathrm{~km}$ (the station AIRB was located approximately $20 \mathrm{~km}$ north of this area), and the height of the stations above

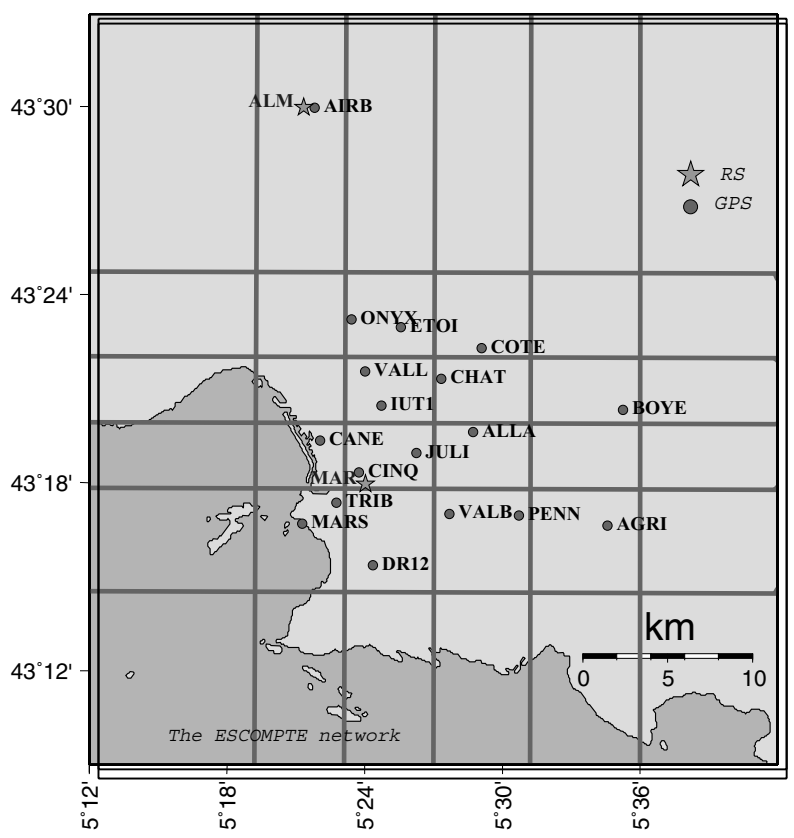

Fig. 1. The ESCOMPTE network. Shown are the GPS stations (circles), the launch sites of the radiosondes (stars), and the horizontal projection of the voxel grid. In the text we refer to the sites using their four (GPS) and three (radio sondes) letter names. 

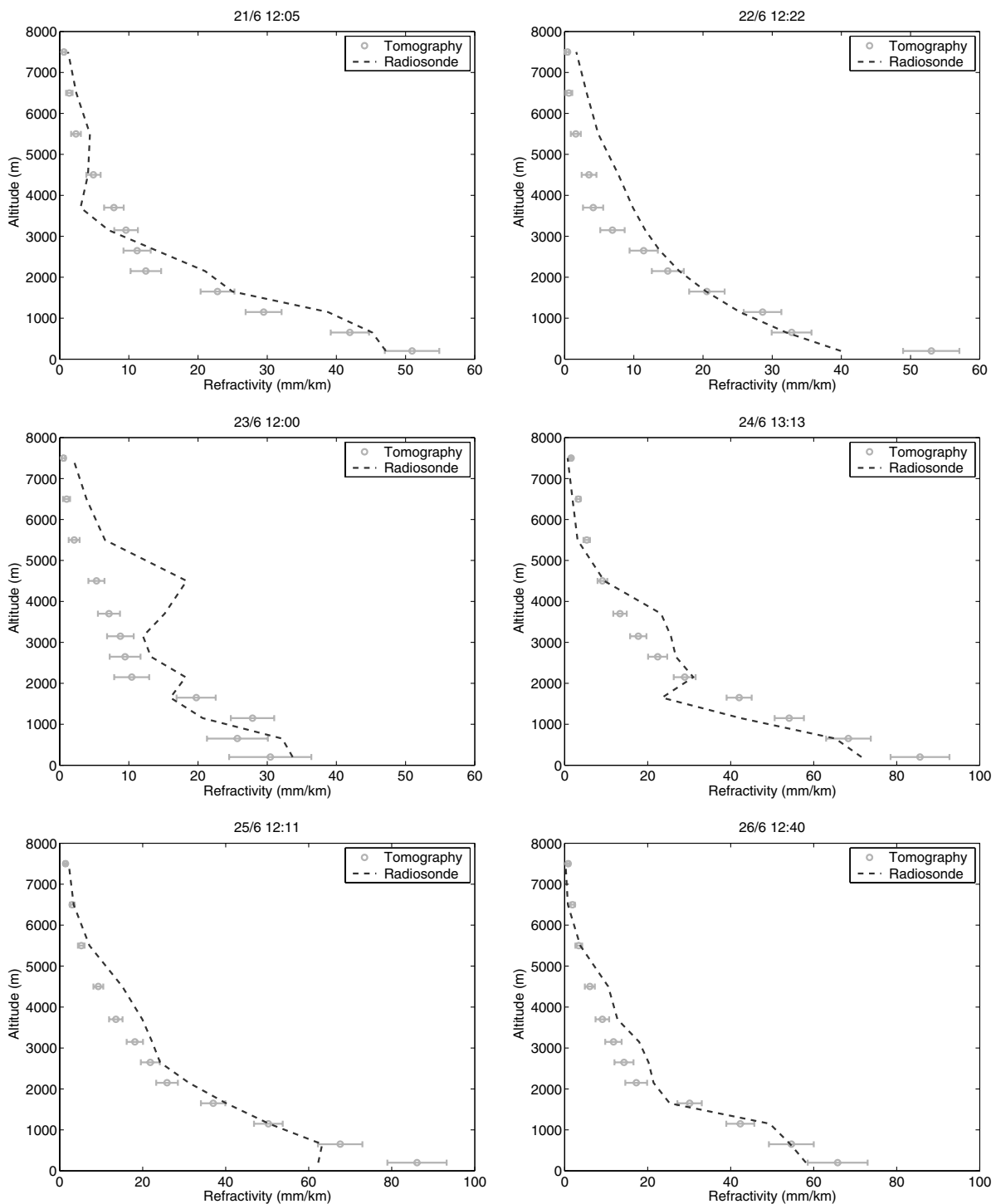

Fig. 2. Retrieved refractivity profiles from tomography and radiosondes above the radiosonde launch site ALM. The profiles are from around mid-day on 21-26 June 2001. Note the scale change between the 23:rd and 24:th of June $\left(\mathrm{mm} \mathrm{km}^{-1}=\mathrm{N}\right.$-units $\left.=10^{-6}\right)$.

mean sea level varied from $13 \mathrm{~m}$ (MARS) to $586 \mathrm{~m}$ (ETOI). All GPS stations used Ashtech receivers except the International GSS Service (IGS) station MARS (Trimble) and the station AIRB (Leica) (Bock et al., 2004). We analysed GPS data acquired during $6 \mathrm{~d}$ in the 2:nd Intensive Observation Period (IOP) (21-26 June).

When we applied the tomographic method to the GPS data, we used a voxel grid with 12 vertical layers and $6 \times 6$ voxels in each vertical layer (see Fig. 1). The thickness of the vertical layers was $500 \mathrm{~m}$ for the lower $4 \mathrm{~km}$, then $1 \mathrm{~km}$ up to $8 \mathrm{~km}$. In each layer the inner $4 \times 4$ voxels were small $(\sim 5 \times 5 \mathrm{~km})$ covering the area with the stations (all except AIRB which was outside this area) and with the outer voxels being larger to allow for observations at lower elevation angels (all observations need to exit the grid at the top). We chose to use such a grid in order to have a high resolution directly above the stations in order to minimize discretization errors arising from the refractivity varying inside the voxel (Nilsson, 2005), while at the same time keep the number of voxels (hence, unknowns needed to be estimated) down. The satellite positions were obtained from the final orbit solutions from IGS (Beutler et al., 1999), and the station coordinates were obtained using GIPSY/OASIS-II (Webb and Zumberge, 1993) and the Precise Point Positioning (PPP) Technique (Zumberge et al., 1997). The hydrostatic delays were estimated using ground pressure measurements at the station VALL, which were extrapolated to the other station locations. The error due to this is discussed in Section 4. An elevation cut-off angle of $7^{\circ}$ was used. 

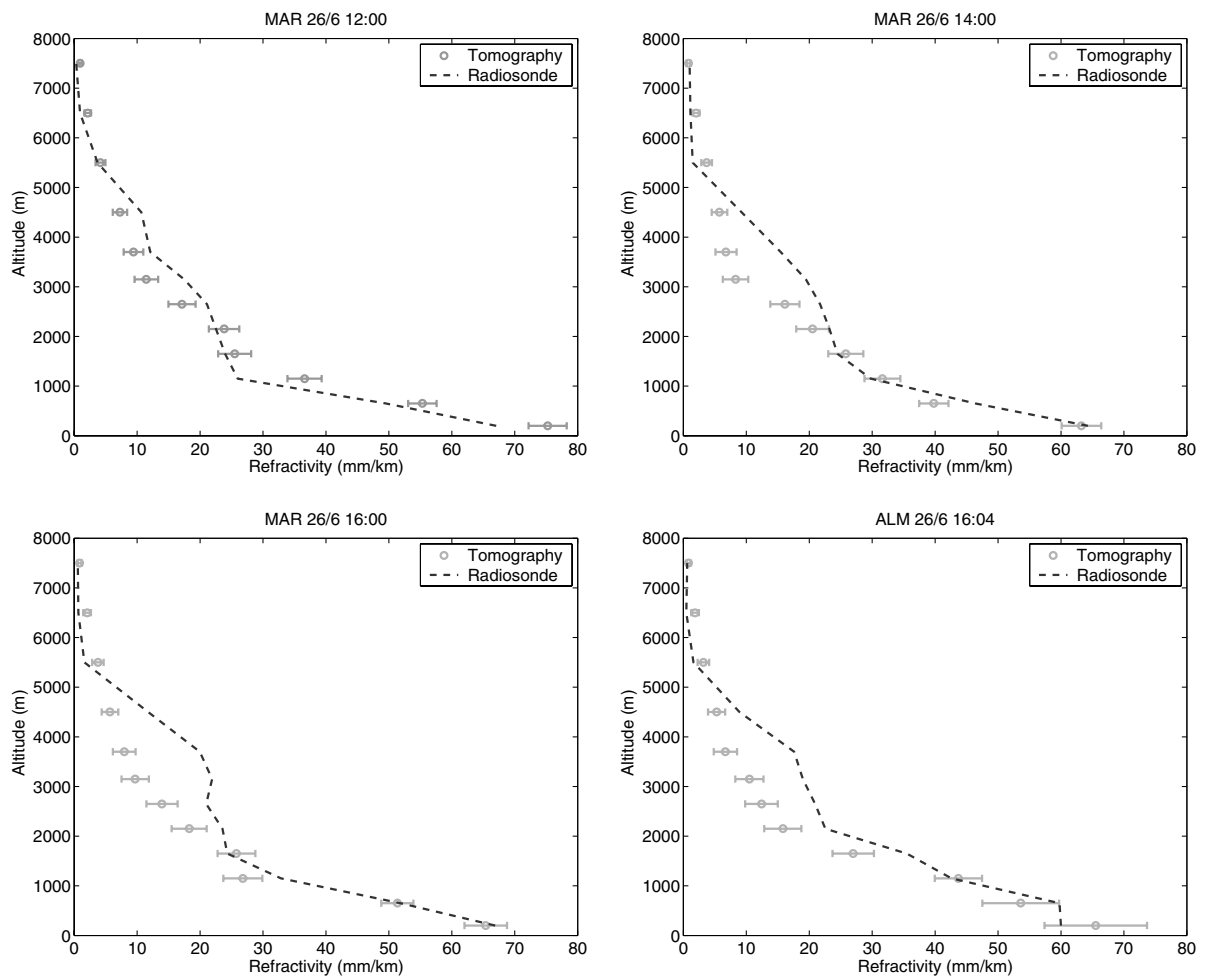

Fig. 3. Retrieved refractivity profiles on 26 June 2001 from tomography and radiosondes. Shown are the profiles above the radiosonde launch site MAR at 12:00, 14:00 and 16:00 UT, and above the radiosonde launch site ALM at 16:04 UT $\left(\mathrm{mm} \mathrm{km}^{-1}=\mathrm{N}\right.$-units $\left.=10^{-6}\right)$.

Fig. 2 shows the retrieved profiles above the Aix-les-Milles (ALM) radiosonde launch site (close to the GPS site AIRB) for the tomographic solution and from radiosondes (for the radiosondes, the mean retrieved refractivity for each layer is displayed) for 21-26 June 2001. As seen, the shapes of the profiles retrieved using tomography agree in general with the radiosonde profiles, especially at the lower altitudes. One reason for the differences between these profiles can be that the radiosonde launch site is located $\sim 20 \mathrm{~km}$ north of most of the GPS sites (all except AIRB), hence, the sensitivity over this location can be expected to be less than over the centre of the network. This is especially important for the last 4 days, when no GPS data from the station at the radiosonde launch site (AIRB) were available. This can explain that for these days, the agreement at the lowest altitude is worse.

A better comparison would be using radiosondes launched in the centre of the network, which occurred on June 262001 in Marseille close to the GPS station CINQ (radiosonde launch site MAR). The retrieved tomographic profiles for this day are shown together with the radiosonde profiles in Fig. 3. These profiles show a better agreement, For example the rapid decrease in the first $\mathrm{km}$ is clearly visible. However, the inversion occurring at around $4 \mathrm{~km}$ at 16:00 is not retrieved illustrating the limited resolution at such high altitudes. In Fig. 3, the retrieved and the radiosonde profiles above the ALM site are also shown. Since this radiosonde launch occurred almost simultaneous to the 16:00 launch at the Marseille station, we can study how well tomography captures the differences in refractivity profiles between the two sites.

Comparing the two profiles at 16:00 in Fig. 3, we note that the radiosondes indicate that the refractivity is decreasing less rapidly at the lower altitudes at ALM compared to the MAR radiosonde launch site. This can also be seen in the retrieved tomographic profiles. Note that the retrieved refractivity in the third layer is much higher for ALM, $44 \mathrm{~mm} \mathrm{~km}^{-1}$ compared to $27 \mathrm{~mm} \mathrm{~km}^{-1}$ for MAR. This is in agreement with the radiosonde profiles.

One reason for the large bias at the higher altitudes may be that the constraints used in the Kalman filter do not allow for any large variations high-up in the atmosphere. A simple exponential profile was used for $C_{n}$ in eq. (4), which may not be the true profile. For example, the changes observed in the radiosonde profiles at around $4 \mathrm{~km}$ altitude on 26 June indicate that the atmosphere was unusually variable at this altitude on that day, probably more variable than what is given by the $C_{n}$ profile used in the tomographic retrieval. To investigate the impact of the assumed $C_{n}$ values on the results, we made a test where the $C_{n}$ values between 2 and $6 \mathrm{~km}$ were constant and equal to the value at $2 \mathrm{~km}$, below this height the profile was the same as before. The result can be seen in Fig. 4 where the profiles at 12:00 and 16:00 are shown. As seen, the bias at high altitudes is reduced. Also, a very small increase $\left(0.65 \mathrm{~mm} \mathrm{~km}^{-1}\right)$ in the 

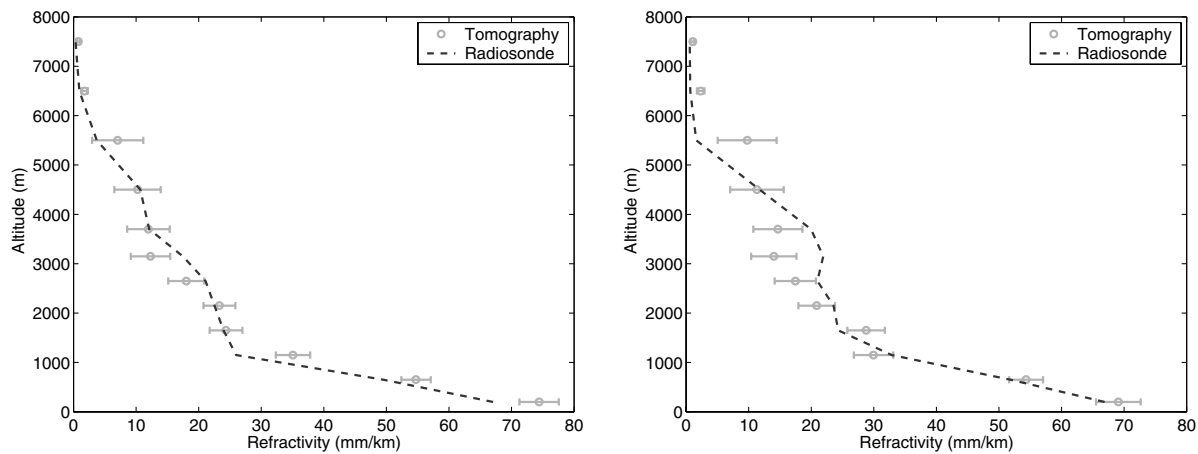

Fig. 4. Retrieved refractivity profiles on 26 June 2001 from tomography and radiosondes. A modified structure constant profile was used in the tomographic estimation. Shown are the profiles above the radiosonde launch site MAR at 12:00 and 16:00 UT $\left(\mathrm{mm} \mathrm{km}^{-1}=\mathrm{N}^{-u n i t s}=10^{-6}\right)$.

Table 1. Average absolute difference between the refractivity of the voxels estimated from tomography and radiosondes. The first six lines are for the profiles in Fig. 2, the next four are for the profiles in Fig. 3, and the last two are for the profiles in Fig. 4

\begin{tabular}{|c|c|c|c|c|c|c|c|c|}
\hline \multirow[b]{2}{*}{ Time } & \multirow[b]{2}{*}{ Site } & \multirow{2}{*}{$\begin{array}{c}\text { Total } \\
\left(\mathrm{mm} \mathrm{km}^{-1}\right)\end{array}$} & \multicolumn{2}{|c|}{$0-2 \mathrm{~km}$} & \multicolumn{2}{|l|}{$2-4 \mathrm{~km}$} & \multicolumn{2}{|l|}{$4-8 \mathrm{~km}$} \\
\hline & & & $\left(\mathrm{mm} \mathrm{km}^{-1}\right)$ & $(\%)$ & $\left(\mathrm{mm} \mathrm{km}^{-1}\right)$ & (\%) & $\left(\mathrm{mm} \mathrm{km}^{-1}\right)$ & $(\%)$ \\
\hline 21 June 12:05 & ALM & 3.5 & 4.6 & 12 & 4.7 & 64 & 1.1 & 39 \\
\hline 22 June $12: 21$ & ALM & 3.6 & 4.2 & 12 & 3.6 & 32 & 2.8 & 69 \\
\hline 23 June 12:00 & ALM & 5.4 & 5.1 & 22 & 5.7 & 38 & 5.4 & 71 \\
\hline 24 June $13: 13$ & ALM & 6.4 & 11.9 & 33 & 6.1 & 24 & 1.2 & 66 \\
\hline 25 June $12: 11$ & ALM & 4.9 & 7.9 & 13 & 4.5 & 19 & 2.2 & 28 \\
\hline 26 June $12: 40$ & ALM & 3.9 & 4.9 & 12 & 5.0 & 28 & 1.6 & 124 \\
\hline 26 June 12:00 & MAR & 3.8 & 6.5 & 18 & 3.5 & 20 & 1.4 & 90 \\
\hline 26 June $14: 00$ & MAR & 3.8 & 2.7 & 7 & 7.0 & 38 & 1.7 & 71 \\
\hline 26 June $16: 00$ & MAR & 4.7 & 2.4 & 7 & 9.1 & 43 & 2.5 & 111 \\
\hline 26 June 16:04 & ALM & 5.2 & 5.3 & 12 & 8.7 & 44 & 1.7 & 118 \\
\hline 26 June $12: 00$ & MAR & 3.0 & 5.5 & 15 & 2.3 & 12 & 1.3 & 80 \\
\hline 26 June $16: 00$ & MAR & 3.5 & 3.0 & 9 & 4.8 & 23 & 2.7 & 211 \\
\hline
\end{tabular}

refractivity between $3200 \mathrm{~m}$ and $3700 \mathrm{~m}$ can be seen at 16:00, giving some indication of the inversion seen in the radiosonde profile.

In Table 1, we present the absolute mean difference and the relative error between the refractivity estimated from tomography and from radiosondes. Shown are the mean for all altitudes, for the lower $2 \mathrm{~km}, 2-4 \mathrm{~km}$, and for $4-8 \mathrm{~km}$. As seen, the relative error is smaller at the low altitudes. The size of the errors are in general in agreement with the simulations in Nilsson and Gradinarsky (2006), including the large relative errors above $4 \mathrm{~km}$.

It is interesting to compare the results to those of other methods. Champollion et al. (2005) analysed ESCOMPTE data from 26 June 2001 with a tomographic method using slant wet delays estimated from the GPS processing software GAMIT (King, 2002; Walpersdorf et al., 2004). The results were approximately the same as presented here; the retrieved profiles agree with the radiosonde profiles at the lower altitudes, but the inversion occurring at 16:00 is not retrieved at all. The same day was also studied by Lutz et al. (2004) where the slant wet delays were used in the tomographic software atmospheric water vapor tomographic software (AWATOS) (Troller et al., 2002). Here too, the inversion at around $4 \mathrm{~km}$ was not detected, and furthermore, the rapid decrease in refractivity at the lower altitudes was not retrieved as well as in this work and in the work by Champollion et al. (2005).

In the work by Lutz et al. (2004), the average difference and the rms variation of the difference between the tomographic solution and the radiosonde profiles were reported. At 12:00 UT these values were $-0.1 \pm 7.2 \mathrm{~mm} \mathrm{~km}^{-1}$, at 14:00 UT $1.0 \pm$ $5.9 \mathrm{~mm} \mathrm{~km}^{-1}$ and at $16: 00 \mathrm{UT} 1.5 \pm 7.1 \mathrm{~mm} \mathrm{~km}^{-1}$. The corresponding values in our solution are $1.1 \pm 5.0 \mathrm{~mm} \mathrm{~km}^{-1},-2.8 \pm$ $4.4 \mathrm{~mm} \mathrm{~km}^{-1}$, and $-3.8 \pm 5.1 \mathrm{~mm} \mathrm{~km}^{-1}$. As seen, the mean differences are smaller in the solution of Lutz et al. (2004), mostly due to the underestimation of the refractivity around $4 \mathrm{~km}$ altitude in our solution. The solutions from Lutz et al. (2004) also have a negative bias at large altitudes, but this is cancelled out 


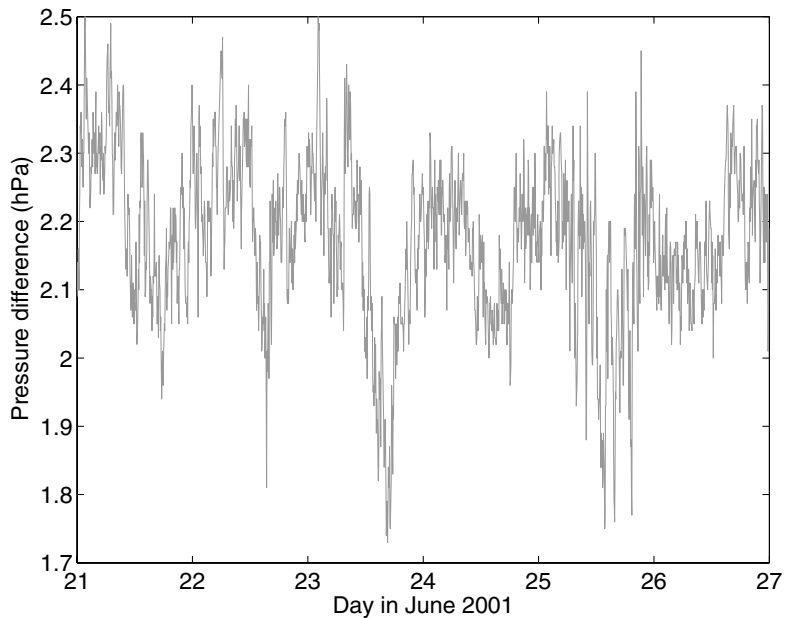

Fig. 5. Pressure difference between Barben $\left(43.6^{\circ} \mathrm{N}, 5.2^{\circ} \mathrm{E}, 165 \mathrm{~m}\right.$ above mean sea level) and Réaltor $\left(43.5^{\circ} \mathrm{N}, 5.3^{\circ} \mathrm{E}, 162 \mathrm{~m}\right.$ above mean sea level). The distance between these locations is $18 \mathrm{~km}$.

by a positive bias a lower altitudes. Furthermore, the rms spread are clearly lower in the solution presented in this work, showing that the shape of the refractivity profile is better retrieved with the new method.

\section{Possible error sources}

There are several error sources that may affect the results. First of all, pressure measurements were not available at all stations. Hence, we had to extrapolate the pressure measurements at one station to all the others. In doing this, we assumed that there were no horizontal gradients in the hydrostatic delay. If such gradients were present, the extrapolated pressure measurements would lead to errors in the hydrostatic delay and hence also in the wet refractivity. One way to investigate the possible presence of hydrostatic gradients is to look for gradients in the surface pressure (since the hydrostatic delay is proportional to the ground pressure). We compared the pressure measurements from two locations (Barben and Réaltor) north of the network, distance $\sim 18 \mathrm{~km}$ from each other. The heights of the locations were approximately the same, $165 \mathrm{~m}$ and $162 \mathrm{~m}$. The difference in pressure between the stations due to the $3 \mathrm{~m}$ difference in height can be expected to be small, less than $0.5 \mathrm{hPa}$ and relatively constant. Fig. 5 shows the pressure differences for the period 21-26 June 2001. As seen, the difference varied between 1.7 and $2.5 \mathrm{hPa}$. Hence, it would seem that some gradients were present, although it should be noted that a major part of the mean difference is likely to be due to biases in the barometers since the higher pressure is observed at Barben which is $3 \mathrm{~m}$ higher than Réaltor. We can conclude that the pressure difference varied less than $1 \mathrm{hPa}$ over $18 \mathrm{~km}$, corresponding to at the most a couple of $\mathrm{mm}$ in the zenith hydrostatic delay $(1 \mathrm{hPa} \approx 2.3 \mathrm{~mm})$. Furthermore, from weather maps (http://www.wetterzentrale.de/topkarten/fsreaeur.html), we can
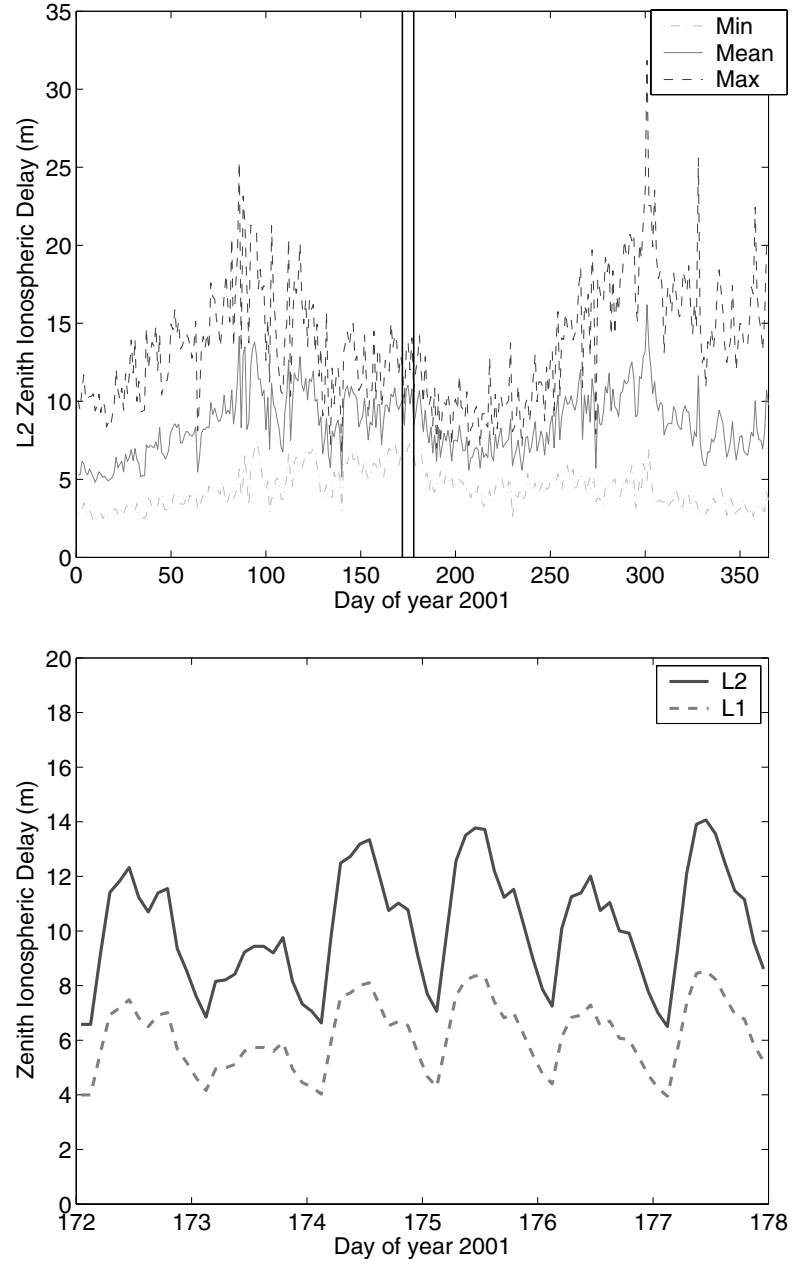

Fig. 6. Top: Ionospheric delay on L2 in 2001. Shown are daily maximum, mean, and minimum values. Bottom: The ionospheric delay on L1 and L2 for the period 21-26 June 2001.

estimate the pressure gradient to be well below $0.05 \mathrm{hPa} \mathrm{km}^{-1}$, although the resolution of these maps is low and hence, the accuracy limited. Hence, we can conclude that the error in the hydrostatic delay estimates due to hydrostatic gradients is a couple of $\mathrm{mm}$ or less in the zenith direction for the investigated period.

We removed the ionospheric delay using the ordinary ionospheric free combination (Hofmann-Wellenhof et al., 2001). This removes the first-order effect of the ionosphere, but higher order terms are also present. The higher order contribution to the ionospheric delay will be $\sim 0.1 \%$ of the first-order contribution (Wang et al., 2005). Hence, higher order terms are more important when the ionospheric activity is high. Investigating ionospheric total electron content (TEC) maps produced by the IGS (Beutler et al., 1999) for the considered period showed that the TEC levels were far from any maximum. In Fig. 6 the zenith ionospheric delay above the network is plotted for the year 2001 and the investigated period. The ionospheric activity reached a maximum in the end of 2001/beginning of 2002, however, as can be seen, 
there was a short period with lower activity in the middle of 2001. Hence, the problem with higher order ionospheric effects can be expected to be at most on the mm level in the zenith direction, which is comparable to the magnitude of the other error sources.

Another possible error source which is difficult to assess is multipath. One station which appears to have large multipath compared to the rest is VALB. When the data from this station were processed with the GAMIT software (King, 2002) the residuals were high and the variations in the zenith wet delay were somewhat different from the rest of the network (Bock et al., 2004). We tested processing the data with our tomographic software excluding this station, but no improvement was observed. Hence, the multipath effect at this single station was not large enough (compared to the multipath at the other stations) to have a significant effect on the results. However, if all stations had multipath problems that would likely have an impact on the results. Multipath is most important at low elevation angles and can be reduced by not using low elevation observations. On the other hand, we will have more observations and the geometry of the tomographic system will be stronger when observations at low elevation angles are used. Hence, using a high elevation angle cut-off will not necessarily give better results. In our investigation, we selected an elevation angle cut-off of $7^{\circ}$ as a compromise, based on earlier experiences.

There exist techniques to reduce the effect of multipath, for example postfit phase residual stacking (Shoji et al., 2004). This technique require a significant amount of representative data in order to estimate systematic residuals as a function of azimuth and elevation angle. This is useful in geodetic positioning of GPS reference networks. The residual stacking technique will, however, remove all systematic effects in the observed phase delay data, including those caused by the atmosphere. For example, if on the average there is more water vapour in a certain direction, this signal will be interpreted as a multipath effect and removed. Even if such effects eventually can be ruled out based on analysis of numerical weather models, a data set much longer than a couple of weeks is needed in order to assess the usefulness of the method. The anticipated short-term variations in the multipath effect caused by changes in the electromagnetic environment due to weather (precipitation etc.) is much more difficult to investigate.

The discretization error, that is, the error due to the approximation that the refractivity is constant in each voxel, will also affect the results. In order to minimize such errors, the horizontal sizes of the voxels above the stations should be small, $\lesssim 10 \mathrm{~km}$ (Nilsson, 2005). In this work, we used voxels with horizontal dimensions approximately $5 \times 5 \mathrm{~km}$ (adjusted slightly to avoid stations at the voxel borders), hence the discretization error could be expected to be small, the slant wet delays are modelled by the voxels with an accuracy of a few $\mathrm{mm}$.

When assessing the quality of the retrieved refractivity field by, for example comparing the refractivity profiles to those obtained using radiosondes, the errors in the radiosonde measure- ments must also be considered. The accuracy of the radiosondes used for comparison in this work (Vaisala RS80) are specified as $0.2{ }^{\circ} \mathrm{C}$ in temperature and $2 \%$ in relative humidity. However, the accuracy will in general be dependent on a number of factors, like the accuracy of the calibration of the sondes, the temperature, the humidity and the presence of clouds (Miloshevich et al., 2006). The accuracy of the radiosondes also decreases with age (Wang et al., 2002). The error in the refractivity from the radiosondes could be a few $\mathrm{mm} \mathrm{km}^{-1}$.

It is also important to remember that GPS tomography gives the refractivity of voxels, that is, averages of the refractivity over large volumes, while radiosondes are in situ measurements. In the figures, the radiosonde measurements are averaged in each voxel to provide values that can be compared to those from the tomographic solution, however, this average is only in height and there may also be horizontal variations in the refractivity. Hence, the refractivities of the voxels estimated using radiosondes may not be equal to the true values. This will give a contribution to the difference between the radiosondes and the tomographic solution. Using eq. (4), we estimate these differences to be of the order a few $\mathrm{mm} \mathrm{km}^{-1}$ at the lower altitudes where the atmosphere is most variable.

\section{Conclusions}

The results of applying our new tomographic method to the ESCOMPTE data generally gives results consistent with previously conducted simulations. The demonstrated average absolute difference between the radiosonde refractivity and the tomographic solution is in general $4-5 \mathrm{~mm} \mathrm{~km}^{-1}$. The refractivity in the lower $2 \mathrm{~km}$ of the troposphere is retrieved with an accuracy of around $10 \%$ most of the time. For example, the rapid decrease in refractivity in the first $\mathrm{km}$ on 26 June is detected by the tomographic method. The results deteriorate for the higher altitudes (although the mean estimation error is lower, but this is a result of the refractivity being low). This was also the case in the simulations presented in Nilsson and Gradinarsky (2006). One reason for this deviation is that the constraints used in the Kalman filter restrict the refractivity in the upper troposphere to low values and low variability. Another reason is that the satellite geometry results in a system of equations insensitive to the variations in refractivity at high altitudes.

The mean estimation errors in Table 1 are slightly higher (by appoximately $1 \mathrm{~mm} \mathrm{~km}^{-1}$ ) than what could be expected given the results from the simulations by Nilsson and Gradinarsky (2006), where the mean estimation error generally was in the range $1-4 \mathrm{~mm} \mathrm{~km}^{-1}$. This is not surprising. First of all, the error sources discussed in Section 4 were either not present (like multipath and higher order ionospheric effects) or not as large (e.g. error in pressure measurements) in the simulations. Furthermore, in the simulations the retrieved refractivity was compared to the true (simulated) refractivity, while here we compare to radiosonde data which also contain errors. 
In the future the method can be developed further, for example by improving the turbulence models used in obtaining the covariance matrix for the Kalman filter, as well as the model for the variation of $C_{n}^{2}$. Our investigations showed that the biases at large altitudes visible in the profiles in Fig. 3 were decreased when using higher values $C_{n}^{2}$ at these altitudes. However, we have no justification for the $C_{n}^{2}$ to have such profile (expect the variations in refractivity at this altitude we see in the radiosonde data). Furthermore, as discussed in Nilsson (2005) the model (4) is valid for correlation between refractivity of two points in space, rather than the correlation between the refractivity of two voxels (i.e. an average of the refractivity in a large volume). Developing and implementing such a model is likely to improve the results.

The results show that GPS tomography can retrieve information about the refractivity field. The analysis also confirmed the limitations of the technique, as for example the limited sensitivity above $4 \mathrm{~km}$. The error sources discussed in Section 4 are expected to have affected the results, however, it is difficult to assess exactly how these errors will impact the retrieved profiles since it depends on how the errors change with direction and their spatial and temporal correlations etc. For example, an error proportional to the wet delay will result in the refractivity profile being biased by a constant factor, while an error behaving like white noise will have a small impact as long as its variance is low. Most likely the impact of the errors will be small as long as the magnitude of the error is much smaller than the wet delay. Many of these errors should be possible to reduce, for example it is possible to have pressure measurements at all stations and by using more than two carrier frequencies (a third GPS frequency will be implemented in the future) higher order ionospheric effects can be reduced (Wang et al., 2005). Furthermore, simulations have shown that including data from other GNSS, like the future Galileo, in the analysis will improve the results (Nilsson and Gradinarsky, 2006). Ground-based GPS tomography may also be useful in order to study horizontal variations with high spatial and temporal resolution. However, the challenge here is to obtain independent data of sufficient resolution and accuracy for validation.

\section{Acknowledgements}

The authors would like to thank all persons in the ESCOMPTE field experiment, and Cédric Champollion for giving us access to the data. We also would like to thank Per Jarlemark for his help in developing the tomographic software, and the two anonymous reviewers for pointing out several issues that needed clarification. This work is financed by the Swedish National Space Board.

\section{References}

Atmospheric Research. 2005. Special issue on the ESCOMPTE field experiment. 74 .
Beutler, G., Rothacher, M., Schaer, S., Springer, T. A., Kouba, J. and co-authors. 1999. The International GPS Service (IGS): An interdisciplinary service in support of Earth sciences. Adv. Space Res, 23, 631-635.

Bevis, M., Businger, S., Herring, T. A., Rocken, C., Anthes, R. A. and co-authors. 1992. GPS meteorology: remote sensing of atmospheric water vapour using the global positioning system. J. Geophys. Res. 97(D14), 15 787-15801.

Bock, O., Doerflinger, E., Masson, F., Walpersdorf, A., Van-Baelen, J. and co-authors. 2004. GPS water vapour project associated to the ESCOMPTE programme: description and first results of the field experiment. Phy. Chem. Earth 29, 149-157.

Brown, R. G. and Hwang, P. Y. C. 1997. Introduction to Random Signals and Applied Kalman Filtering. John Wiley \& Sons, 3rd edition.

Champollion, C., Mason, F., Bouin, M.-N., Walpersdorf, A., Doerflinger, E. and co-authors. 2005. GPS water vapour tomography: preliminary results from the ESCOMPTE field experiment. Atmospheric Research, 74, 253-274.

Cros, B., Durand, P., Cachier, H., Drobinski, Ph., Frejafon, E. and coauthors. 2004. The ESCOMPTE program: an overview. Atmospheric Research, 69, 241-279.

Elósegui, P. and Davis, J. 2003. Accuracy assessment of GPS slantpath determinations. In Proc. International Workshop on GPS Meteorology, Tsukuba, Japan. URL http://dbx.cr.chiba-u.jp/Gps_Met/ gpsmet/index.html.

Emardson, T. R., Elgered, G. and Johansson, J. M. 1998. Three months of continuous monitoring of atmospheric water vapour with a network of Global Positioning System receivers. J. Geophys. Res. 103(D2), 1807-1820.

Flores, A., de Arellano, J. V.-G., Gradinarsky, L. P. and Rius, A. 2001. Tomography of the lower troposphere using a small dense network of GPS receivers. IEEE Trans. Geosci. Remote Sensing 39, 439-447.

Gradinarsky, L. and Jarlemark, P. 2004. Ground-based GPS tomography of water vapour: Analysis of simulated and real data. J. Meteorol. Soc. Japan 82, 551-560.

Hofmann-Wellenhof, B., Lichtenegger, H. and Collins, J. 2001. GPS: Theory and Practice. Springer-Verlag, 5th edition.

King, R. W. 2002. Documentation for the GAMIT GPS analysis software. Technical report, MIT. URL http://www-gpsg.mit.edu/ simon/gtgk/GAMIT.pdf.

Lutz, S., Troller, M., Somieski, A., Walpersdorf, A., Doerflinger, E. and co-authors. 2004. GPS tomography and remote sensing techniques for water vapor determination in the ESCOMPTE campaign. In Proceedings of the IGS Workshop \& Symposium, Berne, Switzerland. URL http://igscb.jpl.nasa.gov/.

Miloshevich, L. M., Vömel, H., Whiteman, D. N., Lesht, B. M., Schmidlin, F. J. and co-authors. 2006. Absolute accuracy of water vapour measurements from six operational radiosonde types launched during AWEX-G and implications for AIRS validation. J. Geophys. Res. 111, D09S10.

Nilsson, T. 2005. Assessment of tomographic methods for estimation of atmospheric water vpor using ground-based GPS. Technical Report 6L, Dept. Radio Space Sci., Chalmers Univ. Tech. Göteborg, Sweden. Nilsson, T. and Gradinarsky, L. 2006. Water vapour tomography using GPS phase observations: Simulaton results. IEEE Trans. Geosci. Remote Sensing 6(14), 2927-2941.

Nilsson, T., Gradinarsky, L. and Elgered, G. 2005. Estimating the 3-D structure of the atmospheric water vapor using GPS phase 
observations. In Proceedings of RadioVetenskap och Котmиnikation, RVK 2005, 521-526, Linköping, Sweden. URL http:// www.es.isy.liu.se/rvk05/_final/00085UyliigccqA_PxHNvocCC.pdf.

Rocken, C., Hove, T. Van, Johnson, J., Solheim, F., Ware, R., Bevis, M. and co-authors. 1995. GPS/STORM - GPS sensing of atmospheric water vapor for meteorology. J. Atmos. Oceanic Technol. 12, 468-478.

Shoji, Y., Nakamura, H., Iwabuchi, T., Aonashi, K., Seko, H. and co-authors. 2004. Tsukuba GPS dense net campaign observations: improving in GPS analysis of slant path delay by stacking one-way postfit residuals. J. Meteorol. Soc. Jpn. 82(1B), 301-314.

Tregoning, P., Boers, R., O'Brien, D. and Hendy, M. 1998. Accuracy of absolute precipitable water vapour estimates from GPS observations. J. Geophys. Res. 103, 28 701-28 710.

Treuhaft, R. N. and Lanyi, G. E. 1987. The effect of the dynamic wet troposphere on radio interferometric measurements. Radio Sci. 22, 251-265.

Troller, M., Bürki, B., Cocard, M., Geiger, A. and Kahle, H.-G. 2002. 3-D refractivity field from GPS double difference tomography. Geophys. Res. Lett. 29, 2149.
Walpersdorf, A., Bock, O., Doerflinger, E., Masson, F., van Baelen, J. and co-authors. 2004. Data analysis of a dense GPS network operated during the escompte campaign: first results. Phys. Chem. Earth 29(23), 201-211.

Wang, J., Cole, H. L., Carlson, D. J., Miller, E. R., Beierle, K. and coauthors. 2002. Corrections of humidity measurement errors from the Vaisala RS-80 radiosonde - Application to TOGA-COARE data. $J$. Atmos. Oceanic Technol. 19, 981-1002.

Wang, Z., Wu, Y., Zhang, K. and Meng, Y. 2005. Triple-frequency method for high-order ionospheric refractive error modelling in GPS modernization. Journal of Global Positioning Systems 4, 291295.

Webb, F. H. and Zumberge, J. F. 1993. An introduction to the GIPSY/OASIS-II. JPL Publ. D-11088, Jet Propul. Lab., Pasadena, California.

Zumberge, J. F., Heflin, M. B., Jefferson, D. C., Watkins, M. M. and Webb, F. H. 1997. Precise point positioning for the efficient and robust analysis of GPS data from large networks. J. Geophys. Res. 102(B3), 5005-5017. 